\title{
FACTORS AFFECTING NURSES’ INTENTION TO EMIGRATE FROM THE COUNTRY IN THE CONTEXT OF THE SATISFACTION WITH EMPLOYMENT SITUATION

\author{
Mariana Dimitrova
} \\ Department of Nursing care, Faculty of Public Health, Medical University of Varna
}

\begin{abstract}
INTRODUCTION: Healthcare professionals' high turnover in our country is an especially topical issue within modern conditions. The reasons behind this ongoing process are largely due to nurses' emigration. Thus, the main task of healthcare managers is to focus their efforts on identifying the factors affecting the attitude of nurses to emigrate abroad.

MATERIALS AND METHODS: For the purpose of an empirical sociological study, in February - April 2014 a direct individual anonymous survey on health professionals' motivation to emigrate abroad was conducted. The opinions of 413 nurses from a university and hospitals for active treatment in Northeastern Bulgaria were included in the survey. A total of 11 types of departments and clinics, characterized by high intensity workflow, were studied.

DELIVERABLES: The results of this analysis indicate significant emigration potential among surveyed nurses. Those who are willing to leave the country are highly educated younger nurses, whose point of view is influenced by personal professional experience. The intention to practice the profession abroad is significantly motivated by various aspects of work satisfaction.

DISCUSSION: Similar to our results, a number of authors in their studies report data revealing the intention to work abroad of predominantly young professionals seeking higher payment and better perspectives for career development.

CONCLUSION: The results demonstrate significant emigration potential among the nurses participating in the survey. Among the individual factors, those which clearly affect the intention to emigrate are professional experience, age and level of educational degree. Work satisfaction compared to experience and age has stronger influence on nurses' attitudes to seek alternative opportunities to work outside the country.
\end{abstract}

Keywords: emigration, satisfaction, attitude, nurses

Address for correspondence:
Mariana Dimitrova
Department of Nursing care, Faculty of Public Health,
Medical University of Varna
55 Marin Drinov Str.
9002 Varna, Bulgaria
e-mail: Mariana.Dimitrova@mu-varna.bg

Received: November 25, 2015

Accepted: December 18, 2015

\section{INTRODUCTION}

Bulgaria, like most countries in the world, is in a critical period in terms of availability of nurses. Multiple years of democratic changes, accompanied by economic problems and increasing territorial disproportions in the economic environment resulted in shortage of human resources in specific professional areas. Many authors suggest that the causes that have led to this negative process are rooted in 
the inadequately implemented Health Reform that has resulted in health care professionals' mass layoffs and emigration (1-7).

Cross-border migration processes are directed to countries with stable economic development, better organized healthcare systems and working conditions. Despite the changes in today's Bulgarian healthcare and education, health professionals are still facing problems and challenges.

The majority of researchers in this field agree that the main reasons for the emigration of health professionals are higher wages, better living and working conditions, career opportunities as well as high prestige of the profession, autonomy and social recognition to be found abroad $(6,8,9)$. According to $\mathrm{N}$. Veleva $(3,6)$, the main reasons for emigration are better living and working conditions in the country of emigration. The motivation to acquire more experience, as well as emigration to raise qualification should not be underestimated as well. As a result, those who remain or return to work in medical establishments are retirement-aged nurses $(3,8)$.

Many authors concluded that work satisfaction is a powerful factor influencing the decision to change. It is no accident that it is also seen as both a factor and a result of a variety of variables at an individual, organizational and positional level (10-13). But since not all needs are equally important to employees, it is not obligatory dissatisfaction with various aspects of employment situation always and in all cases to result in an intention for a change.

The OBJECTIVE of this paper is to identify the factors that have the greatest impact on nurses' work satisfaction provoking attitudes to emigrate abroad.

\section{MATERIALS AND METHODS}

For the purpose of the empirical sociological study, in February - April 2014 a direct individual anonymous questionnaire on health professionals' motivation to emigrate abroad was held. The opinion of 413 nurses from university and district general hospitals for active treatment in Northeastern Bulgaria was surveyed. A total of 11 types of wards and clinics, characterized by high intensity workflow, were studied. Data were processed statistically with SPSS v.20.0 statistical software and includes variation, comparative, correlation and multiple regression analyses.

\section{RESULTS}

The objective of analysis in this study are individual characteristics and different aspects of work environment affecting the intention to emigrate abroad. The questionnaire included 25 questions divided into seven sections - demographics, turnover, satisfaction, organizational capabilities, role conflict and degree of clarity, workload and stress.

The results of the study provide clear evidence that every second nurse (49.60\%) has the attitude to emigrate abroad. If the answer "rather yes" (16.70\%) is added to this result, the percentage of prospective immigrants increases significantly (Fig. 1).

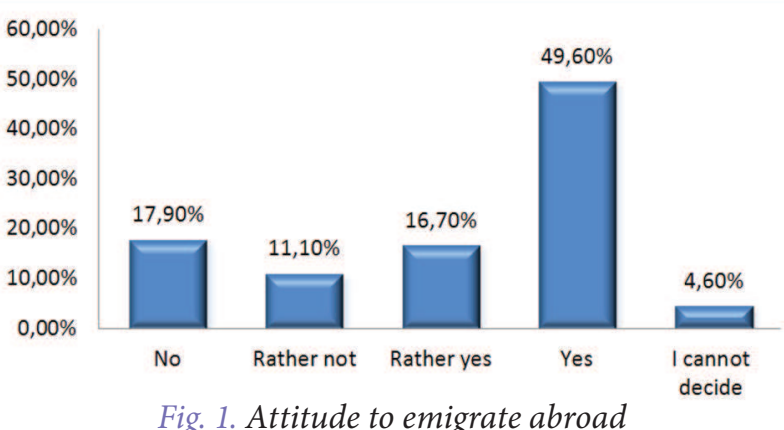

The attitudes of nurses to work abroad are also influenced by age. Younger nurses (mean age $=41.2$ years) are more determined to take this step compared to their older colleagues (mean age $=48.4$ ) who would rather stay and work in the country $(\mathrm{F}=8.52$, $\mathrm{p}<0.001$ ) (Fig. 2).

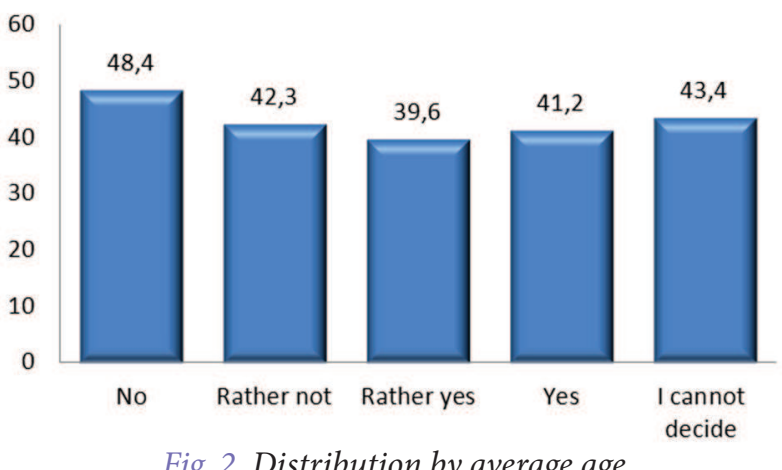

Educational level influences the desire to practice the profession abroad. Nurses who have acquired the degree of Master indicate greatest willingness to 
leave the country $(61.20 \%)(\chi 2=33.34 ; \mathrm{p}<0.05)$. Also, data reveal that the higher the acquired degree, the greater is the desire to work abroad (Fig. 3).

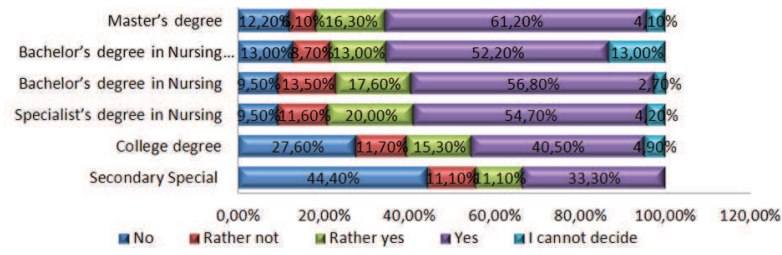

Fig. 3. Distribution by education and desire to work abroad

The survey data show that job satisfaction of the supervisor $(\chi 2=26.61 ; p>0.05)$ and relationships with colleagues are not decisive for the emigration of health care professionals $(\chi 2=17.98 ; \mathrm{p}>0.05)$.

As for the satisfaction with the organization of work, results reveal a significant difference in the attitudes of nurses to practice their profession abroad $(\chi 2=31.61 ; \mathrm{p}<0.01)$. Almost half of the nurses who are satisfied with the organization of work, would remain to work in Bulgaria (48.60\%), and $34.60 \%$ of those who are not satisfied declare their intention to leave the country (Fig. 4).

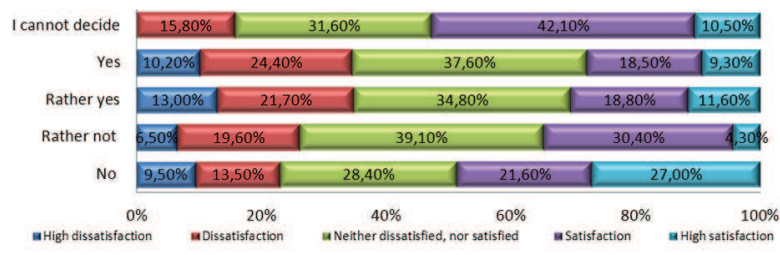

Fig. 4. Relationship and influence between satisfaction with the organization of work and the attitudes to practice abroad

Analysis of the results related to wages shows a difference of opinion among nurses $(\chi 2=30.19$; $\mathrm{p}<0.05)$. A significant proportion of nurses who declare their intention to practice abroad, express high dissatisfaction with their wages (42.0\%). Meanwhile, $12.7 \%$ of the nurses who have expressed their explicit desire to leave the country are satisfied with the remuneration they receive. On the other hand, $24.30 \%$ of the nurses who express a high dissatisfaction with wages would not leave the country (Fig. 5).

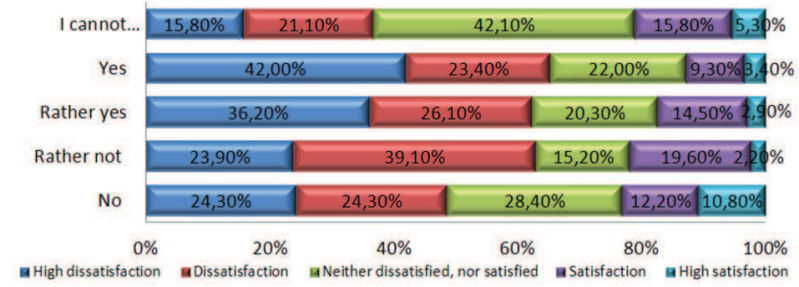

Fig. 5. Relationship and influence between satisfaction with wages and attitudes to practice the profession abroad

Survey results demonstrate that satisfaction with development opportunities is a factor that affects nurses' attitude towards emigration to varying degrees $(\chi 2=32.43 ; \mathrm{p}<0.01)$. Dissatisfaction with development opportunities provokes higher percentage of nurses to seek work abroad (46.40\%) (Fig. 6).

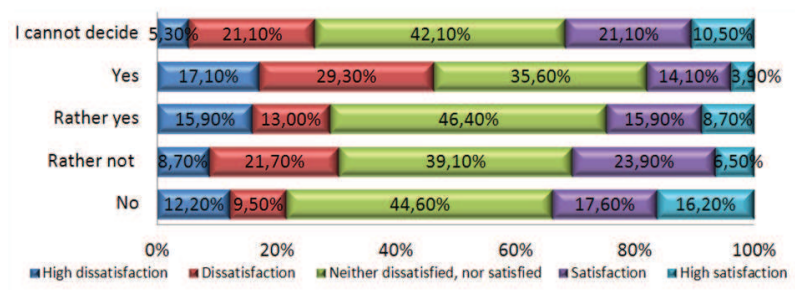

Fig. 6. Relationship and influence between satisfaction with progress opportunities and the attitudes to practice the profession abroad

Availability of medical equipment in the surveyed sectors suggests it to be full and changed and renewed in a timely manner given its intensive use. Nurses who hesitate to work abroad are mostly dissatisfied with the conditions of work: respectively $47.90 \%$ are nurses who answer rather not and $43.40 \%$ for nurses who answer rather yes. However, we can notice significant difference in the desire to emigrate $(\chi 2=46.00 ; p<0.001)$. Poor working conditions, insufficient provision of equipment and supplies generate desire to work in better working conditions outside the country in $37.50 \%$ of dissatisfied nurses. On the other hand, satisfaction with good equipment and supply provision is the reason $43.20 \%$ of the nurses surveyed to share their desire to work in the country (Fig. 7).

Results from the multiple regression step analysis show that of all factors examined, the leading predictor having the greatest impact on the desire to practice the profession abroad is work experi- 


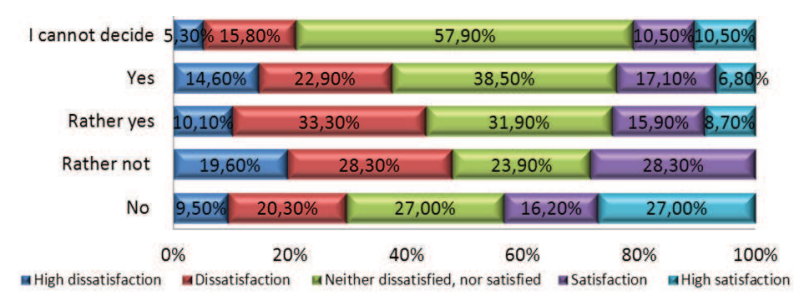

Fig. 7. Relationship and influence between the satisfaction of equipment and supply provision and the intention to practice the profession abroad

ence $(\beta=0.269 ; p<0.000)$, followed by the opportunity for progress and development $(\beta=0.157 ; \mathrm{p}<0.001)$ educational level $(\beta=0.126 ; p<0.01)$ and age $(\beta=0.106$; $\mathrm{p}<0.01$ ).

\section{DISCUSSION}

The studies conducted in recent years relating to healthcare professionals' attitude to emigrate from the country confirm our results $(3,6,12)$. In support of these results we present data of the Bulgarian Association of Healthcare Professionals according to which over the past 20 years almost $50 \%$ of nurses have left the country or the profession.

Similar to our results, the study of Hr. Hristova (12) demonstrated significant emigration potential among nurses (68.50\%), as well as that there is higher emigration propensity among nurses at younger age and with higher education (12). Higher education is associated with better alternatives at the labor market and on the other hand increases individual expectations.

In her studies N. Veleva also produced evidence indicating that those who are willing to work abroad are mostly young professionals seeking higher wages and career opportunities which results in a distortion of the demographic composition of nurses in the country $(3,8)$.

These results are not a surprise to us; young nurses have higher expectations related to professional development and improvement of professional qualification as well as opportunities for better realization. On the other hand, this may be due to the fact that older nurses approach retirement or experience greater work satisfaction and are committed to the institution.

Professional satisfaction is influenced by multiple factors related to personal characteristics and work environment. The analysis of various aspects of work environment shows varying degree of influence on the intention to practice abroad.

There is no doubt that dignified and adequate remuneration of the work done is one of the important motivating factors for employing and retaining good professionals. Health professionals' decision to emigrate abroad is largely linked with better wages in the countries of emigration, but remuneration is not the leading factor for all nurses. The difference lies in the fact that despite their dissatisfaction, a relatively vast majority of them state their desire to remain in the country. It turns out that the decision to emigrate abroad is influenced by other factors as well.

Under the conditions of urgency, nurses are required to be resourceful, with quick reactions and to take responsibility in the implementation of work. Good organization of work by managers is an investment in staff retention. However, a relatively large proportion of respondents are dissatisfied with the organization, equipment and supply provision, which largely supports the decision to practice the profession abroad.

Reasons for emigration are not always due to economic reasons; professional development is also important for the individual. Opportunities for professional development and growth are perceived as a factor which increases satisfaction due to the positive changes that may occur for the employee, such as occupying a higher position within the organization.

\section{CONCLUSION}

The survey results suggest that emigration potential is significant among the nurses surveyed. From the individual factors, those which affect the intention to emigrate are professional experience, age and level of educational degree. Work satisfaction has a major influence on nurses' attitudes to seek other alternative opportunities to work outside the country.

\section{REFERENCES}

1. Borisov V. Health Management with foundations of health policy. Sofia: Filvest; 2003. Bulgarian.

2. Vekov T. Health reform in Bulgaria 1999 - 2000. Sofia: Ciela; 2009. Bulgarian.

3. Veleva N. Status and trends of the labor market for nurses in Bulgaria. Autoreference of dissertation for awarding the educational and scientific degree 
Doctor. Pleven: 2013. Bulgarian. Available from: http: //www.mu-pleven.bg/procedures

4. Dimova A, Popova M, Rohova M. Health reform in Bulgaria. Varna: Open Society Foundation; 2007. Bulgarian.

5. Zahov V. Human resources management in medical institutions. Health Policy and Management. 2008;(6):83-4. Bulgarian.

6. Rohova M, Mutafova E, Kostadinova T. Economic crisis and migration of health professionals. Varna: International Scientific Conference; 2010. Bulgarian.

7. Shopov D, Stoev T. Professional realization and motivation of nurses. Nursing. 2015;47(1):25-9. Bulgarian.

8. Veleva N. Status and trends in the European labor market in nursing. Social Medicine. 2006;1(2):55-7. Bulgarian.

9. Lecheva Z. Conflicts between professional requirements and the social status of nurses. Management and Education. 2012;8(3):130-5. Bulgarian.

10. Boyle DK, Miller PA. Focus onnursingturnover: a system centered performance measure. Nursing Management. 2008;39(6):16.

11. Applebaum D, Fowler S, Fiedler N, Osinubi O, Robson M. The impact of environmental factors on nursing stress, work satisfaction, and turnover intention. Nursing Administration. 2010;40(7-8):323-8.

12. Hristova H. Migration - characteristics and attitudes of medical professionals. Varna: Master's thesis; 2009. Bulgarian.

13. Ma JC, Lee PH, Yang YC, Chang WY. Predicting factors related to nurses intention to leave, work satisfaction, and perception of quality of care in acute care hospitals. Nursing Economics. 2009; 27(3):178-84. 